\title{
CICATRIZAÇÃO DE ANASTOMOSES COLÔNICAS NA VIGÊNCIA DE OBSTRUÇÃO INTESTINAL . ESTUDO EXPERIMENTAL EM RATOS ${ }^{1}$
}

\author{
THE EFFECT OF COLON OBSTRUCTION ON COLONIC \\ ANASTOMOTIC HEALING
}

\author{
Bezuti MT, \\ Omar Féres $^{3}$ \\ Antonio Dorival Campos ${ }^{4}$ \\ Francisco Aprilli ${ }^{3}$ \\ José Joaquim Ribeiro da Rocha ${ }^{3}$ \\ Ricardo dos Santos Garcia ${ }^{5}$ \\ Orcina Fernandes Duarte Joviliano
}

\section{RESUMO}

Introdução - A cicatrização de anastomoses intestinais vem sendo estudada com ênfase às técnicas de sutura e materiais empregados na confecção das anastomoses, bem como à melhor compreensão dos efeitos de diversos fatores sobre a cicatrização. Observa-se número não desprezível de complicações nas anastomoses de cirurgias colorretais e a obstrução colônica é referida como um dos fatores determinantes. Objetivo - Estudar a cicatrização de anastomoses no cólon de ratos na vigência de obstrução intestinal. Métodos Os animais $(n=39)$ foram divididos em: Grupo I (Submetidos à obstrução intestinal induzida quatro dias antes da anastomose, $\mathrm{n}=22$ ) e Grupo II (Controles, $\mathrm{n}=22$ ). As anastomoses colônicas foram confeccionadas por técnica padronizada e, sete dias após, os segmentos que as continham foram analisados e ressecados para dosagem de hidroxiprolina. Resultados - As complicações foram mais frequentes nos animais com obstrução (11 ratos=50\%) que nos controles ( 3 ratos $=17,7 \%), p<0,05$. A média dos valores de hidroxiprolina foi maior no grupo I $(975,0 \mathrm{x}$ 872,0), p >0,05. Discussão - A anastomose no cólon de rato com obstrução intestinal está associada a maior número de complicações que podem ser explicadas pela presença de fatores como: maior dificuldade técnica na confecção da anastomose pela desproporção entre bocas, maior desnutrição, impactação de fezes à montante, translocação bacteriana e isquemia. A semelhança estatística entre os grupos quanto à dosagem de hidroxiprolina sugere que a cicatrização das anastomoses colônicas dos ratos com obstrução intestinal, na ausência de complicações, segue o mesmo processo de síntese de colágeno que a dos controles. Disponível em URL: http://www.scielo.br/acb

Descritores - Cicatrização de anastomoses; anastomoses colônicas; obstrução intestinal

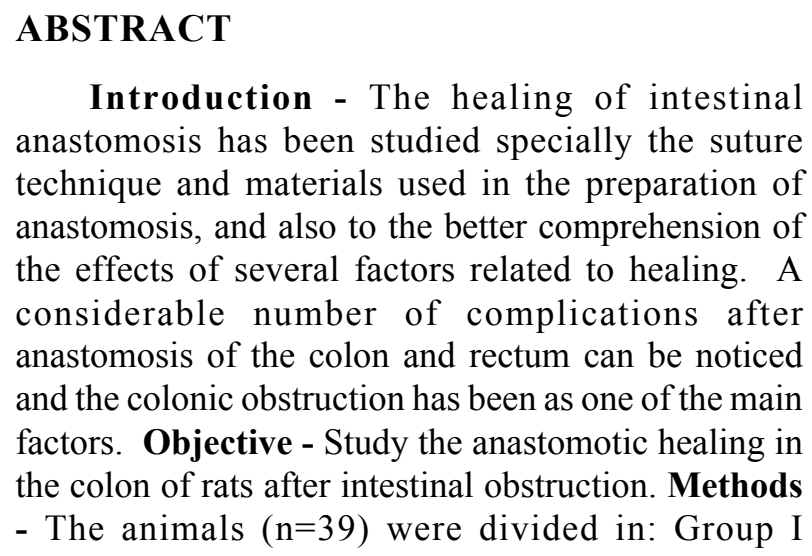
factors. Objective - Study the anastomotic healing in - The animals $(n=39)$ were divided in: Group I

Introduction - The healing of intestinal anastomosis has been studied specially the suture technique and materials used in the preparation of anastomosis, and also to the better comprehension of the effects of several factors related to healing. A considerable number of complications after anastomosis of the colon and rectum can be noticed and the colonic obstruction has been as one of the main the colon of rats after intestinal obstruction. Methods (submitted to intestinal obstruction induced four days before of the anastomoses, $n=22$ ) and Group II

1 Trabalho realizado pela Dsiciplina de Coloproctologia no Departamento de Cirurgia e Anatomia da FMRP - USP

2

3 Docente da Disciplina de Coloproctologia do Depto de Cirurgia e Anatomia da FMRP-USP

4 Docente do Departamento de Medicina Social da FMRP-USP

5 Pós-graduando da Área de Clínica Cirúrgica do Depto de Cirurgia e Anatomia da FMRP-USP 
(Controls, $\mathrm{n}=22$ ). The colonic anastomosis were made by a standardized technique and, seven days later, the segments which them were reviewed, resected and analyzed for a hydroxyproline dosage. Results - The complications were more usual in the animals with obstruction (11 rats: $50 \%$ ) than in the controls ( 3 rats: $17,7 \%), p<0,05$. The median value of hydroxyproline was higher in the Group I $(975,0 \times 872,0), p>0,05$. Conclusion - The anastomosis in the rat's colon with intestinal obstruction is related to more complications. This can be explained by the following factor's: more technical difficulty in the preparation of the anastomosis caused by different diameter of the bowel, higher undernourishment, proximal faecal retention, bacterial translocation and ischaemia. The statistical similarity between the groups regarding to the dosage of hydroxyproline suggests that the healing of the rats' colonic anastomosis with intestinal obstruction, in the absence of complications, follows the same process of collagen synthesis as the controls ones.

Key words - colonic healing, colon obstruction, anastomotic healing

\section{INTRODUÇÃO}

A cicatrização das anastomoses realizadas no tubo digestivo representa preocupação constante, sendo que a deiscência destas suturas prolonga o tempo de internação elevando os custos hospitalares. Tal fator resulta em alta morbidade e pode culminar na morte do paciente $^{1,2}$.

Nos últimos dois séculos, a cicatrização de anastomoses intestinais vem sendo estudada de modo veemente por vários autores, com ênfase às técnicas de sutura e materiais empregados na confecção das anastomoses, bem como melhor compreensão dos efeitos de diversos fatores sobre a cicatrização destas anastomoses.

HALSTED, em 1887, concluiu que a submucosa era a camada mais importante a ser incluída nos pontos de sutura, após trabalhar experimentalmente com cães, conceito ainda aceito por ser esta a camada que possui maior conteúdo de colágeno. Preconizou ainda que as anastomoses intestinais fossem realizadas com pontos separados em plano único extramucoso para evitar penetração de agulha na luz intestinal ${ }^{3}$.

Estudando anastomoses intestinais em plano único com pontos separados, em trabalhos clínicos ou experimentais realizados sob diversas condições, vários autores encontram vantagens deste tipo de sutura sobre aquela em dois planos. As anastomoses em plano único além de serem mais anatômicas apresentam revasculari- zação mais precoce, são seguras, produzem estreitamento luminal mínimo e oferecem melhores condições para a cicatrização.A sutura em dois planos apresenta fenômenos de reparação mais intensos e conduz a maior fibrose, contudo apresenta maior resistência tênsil quando comparada à sutura em plano único ${ }^{4}$.

Com relação à aproximação das bordas, os piores resultados são relatados quando se utilizam suturas com eversão, que apresentam maiores índices de deiscência tênsil do que a sutura por inversão.

A sutura contínua tem sido atestada em vários trabalhos clínicos recentes ${ }^{5}$. HOUDART e cols.(1985) não encontraram diferenças clínicas, histológicas e microangiográficas entre suturas contínuas e com pontos separados argumentando ainda a redução no número de nós e a rapidez da operação $0^{6-9}$.

Em considerável número de pesquisas demonstraram-se vários outros fatores que podem prejudicar o processo de cicatrização das anastomoses intestinais tais como os efeitos negativos da desnutrição e deficiência de proteínas ${ }^{2}$, da carência de vitaminas ${ }^{10}$, da anemia grave ${ }^{11}$, da isquemia ${ }^{4}$, dos diabetes mellitus ${ }^{12}$, quimioterápicos $^{13}$, de prostaglandinas ${ }^{14}$, da uremia $^{15}$ entre outros fatores.

A reação inflamatória ocorre como resposta às mais diversas agressões ou fatores irritantes. Esta reação compreende uma seqüência ordena de fenômenos que possibilitam a restauração da área lesada, caso haja cessação do fator desencadeante ou cronificação do processo. A infecção local ou distante exerce efeito inibitório sobre a cicatrização de feridas em ratos ${ }^{16}$. Esta, por determinar inflamação excessiva e aumentar a atividade da colagenase, contribui para deiscência de anastomoses ${ }^{17}$.

A obstrução de cólon é uma situação comum na prática médica e está associada a várias doenças como câncer de cólon, doença diverticular, megacólon chagásico e doenças inflamatórias intestinais entre outras ${ }^{18}$.

Resta ainda muita controvérsia quanto a abordagem cirúrgica a ser adotada: em uma tempo (ressecção e anastomose primária) ou dois tempos (ressecção com colostomia) ${ }^{19}$. A obstrução do cólon é uma emergência médica que necessita, na maioria das vezes, conduta cirúrgica imediata ${ }^{20}$.

Observa-se um grande número de complicações das anastomoses em cirurgias do cólon como deiscências, abscessos perianastomóticos e sepse abdominal ${ }^{21}$.

O presente estudo tem como objetivo estudar a influencia da obstrução intestinal sobre a cicatrização das anastomoses e a sua relação como o número de complicações. 


\section{MÉTODOS}

\section{Considerações gerais}

As intervenções cirúrgicas foram realizadas no laboratório de Cirurgia Experimental do Departamento de Cirurgia e Anatomia da FMRP-USP.

Foram operados 60 ratos e realizadas as anastomoses, pela mesma técnica, no intestino grosso. Os animais foram divididos em dois grupos: Grupo I (obstrução intestinal) constituído por animais que tiveram o intestino grosso obstruído quatro dias antes da anastomose, Grupo II (controle) constituído por animais que foram submetidos a um procedimento semelhante, porém sem que o intestino grosso fosse obstruído. O sacrifício ocorreu no sétimo dia após a anastomose. Realizou-se estudo macroscópico da cavidade peritoneal e da cicatrização através da dosagem de hidroxiprolina.

\section{Animais}

Ratos da raça Wistar do sexo masculino aparentemente saudáveis, pesando entre 300 e $350 \mathrm{~g}$, oriundos do Biotério Central da FMRP-USP.

\section{Anestesia}

Os animais foram submetidos à anestesia geral inalatória com éter sulfúrico, sendo considerados

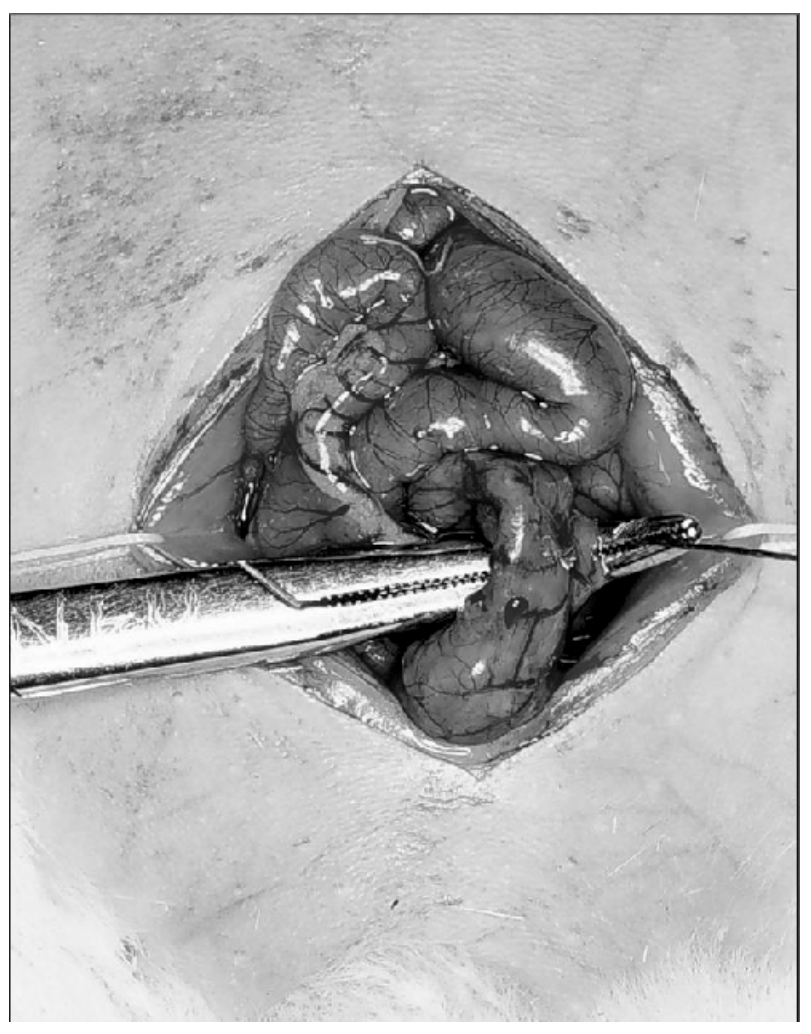

anestesiados quando estes apresentaram respiração regular e superficial, além da flacidez da musculatura esquelética, com a ausência de reflexos.

A anestesia foi mantida com a utilização de cone nasal contendo algodão embebido com éter.

\section{Preparo do campo operatório e acesso à cavidade abdominal}

O animal foi colocado em decúbito dorsal sobre uma calha de madeira sendo os membros fixados com fita esparadrapo. Em seguida foi realizada a tricotomia da parede abdominal anterior.

Como via de acesso à cavidade abdominal foi realizada incisão mediana com aproximadamente $3 \mathrm{~cm}$ de extensão e foram colocados afastadores autoestáticos na parede abdominal.

\section{Descrição da técnica de obstrução}

A obstrução foi realizada na transição retossigmóide perfurando-se com uma pinça hemostática através da borda mesentérica, sem romper nenhum vaso e passamos um fio de algodão 2-0. No grupo I (obstrução) o fio foi amarrado obstruindo-se a luz intestinal. No grupo II(controle) o fio só foi passado sem se realizar a obstrução.

A parede abdominal foi fechada em plano único com fio de nylon 4-0 com sutura continua (Figura 1).

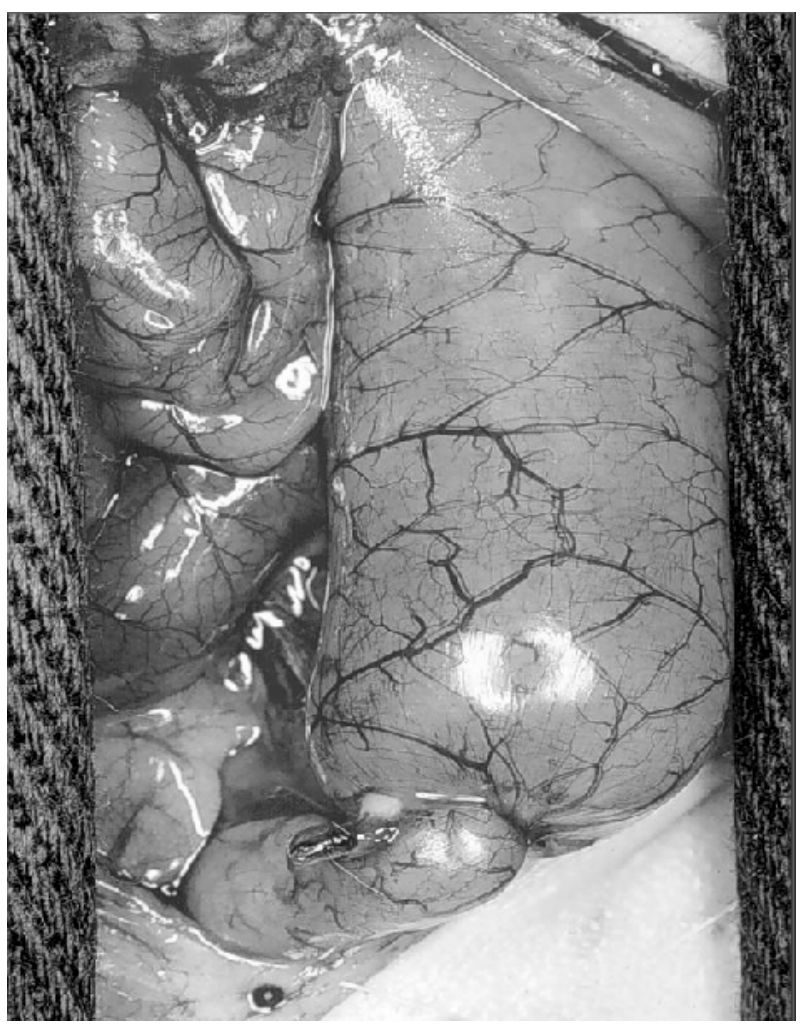




\section{Pós-operatório}

Após a operação os animais foram colocados em gaiolas em grupos de quatro onde receberam alimentação "ad-libitum" até o quarto dia de pós-operatório, quando foram reoperados. Os animais que morreram neste período foram excluídos da analise.

\section{Descrição da técnica das anastomoses}

A anastomose foi realizada no local da obstrução previamente realizada sendo retirado um segmento de $0,5 \mathrm{~cm}$ no grupo controle na transição retossigmóide sendo retirado também um segmento de $0,5 \mathrm{~cm}$. Foram confeccionadas em plano único de sutura envolvendo todas as camadas, com pontos contínuos de polipropileno 6-0 agulhado.

Os segmentos intestinais suturados foram mantidos por um ponto ancorado colocado na borda mesen-

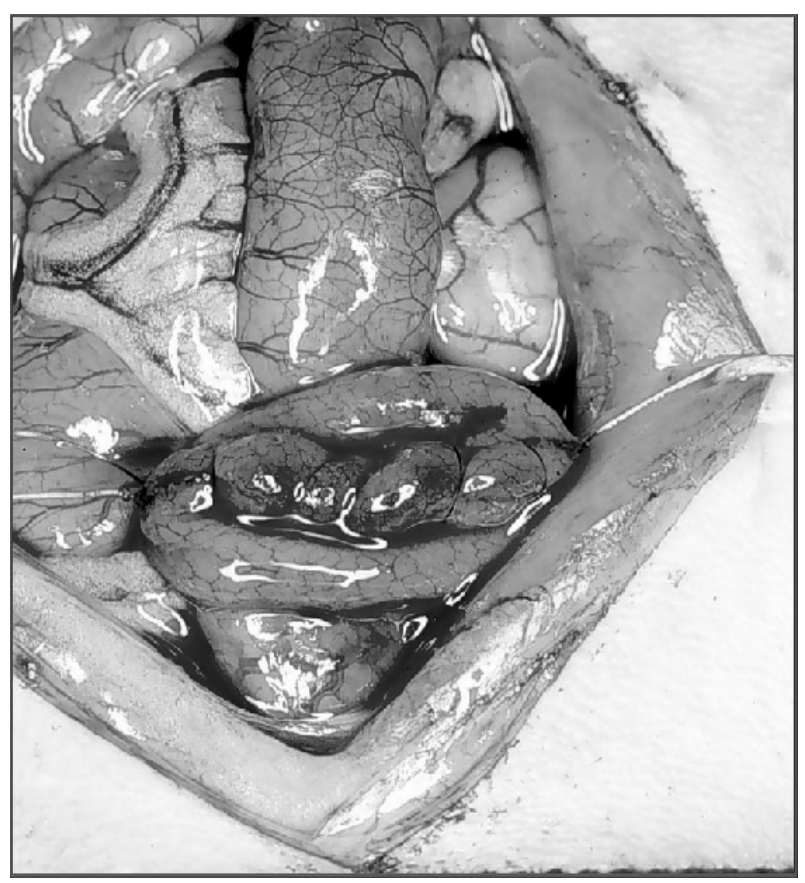

A parede abdominal foi fechada em dois planos de sutura com fio de nylon 4-0 com agulha curva cilíndrica $2,5 \mathrm{~cm}$. O primeiro plano constituído pelo peritônio, muscular e aponeurose, foi aproximado com sutura continua simples e o segundo, a pele com sutura continua em "U".

\section{Pós-operatório}

Após a operação os animais receberam alimentação "ad libitum" até o sacrifício, no sétimo dia pósoperatório. térica e o segmento distal reparado na borda antimesentérica.

A sutura da hemicircunferência posterior foi iniciada na borda mesentérica no ponto ancorado, com pontos passados a cerca de $1 \mathrm{~mm}$ das extremidades livres a intervalos de aproximadamente $1,5 \mathrm{~mm}$. A agulha, em cada ponto, foi introduzida pela mucosa, atravessou todas as camadas intestinais, emergindo pela superfície serosa para, em seguida, penetrar pela serosa e emergir na mucosa da outra extremidade a ser coaptada.

A sutura da hemicircunferência anterior começou no ponto ancorado na borda antimesentérica, com pontos de maneira semelhante, obedecendo ao sentido mucosa-serosa em uma das extremidades e serosamucosa na outra. Para completar a anastomose, na borda mesentérica o último ponto foi unido com o ponto ancorado inicial do segmento posterior (Figura 2).

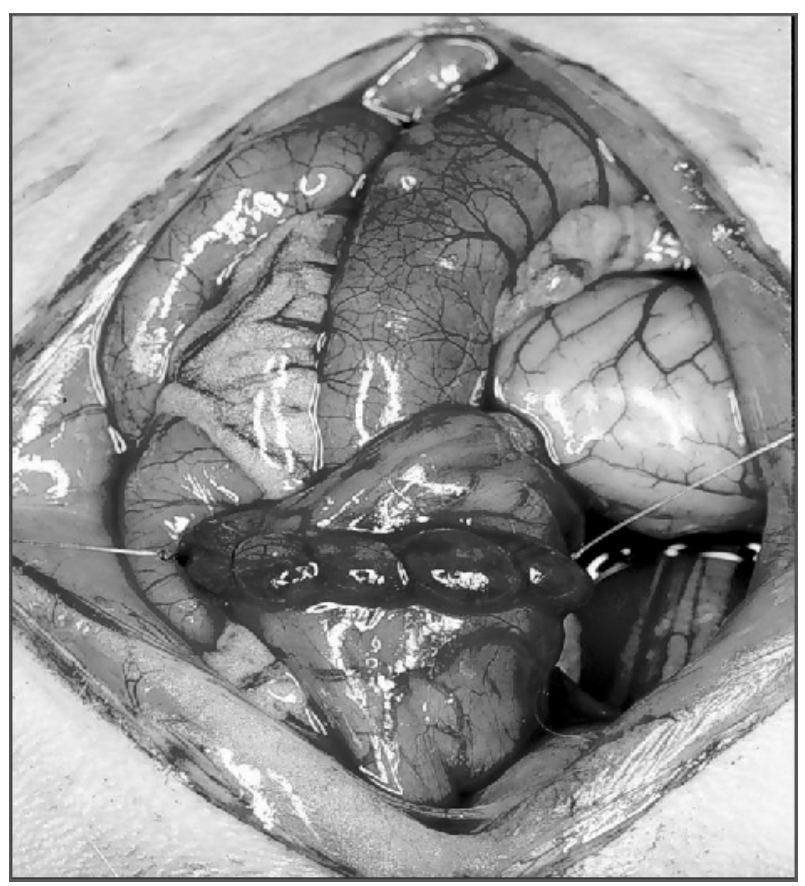

\section{Eutanásia}

Os animais foram anestesiados por técnica à utilizada na ocasião das operações. Sem nenhum cuidado de anti-sepsia, abriu-se a cavidade abdominal por meio de ampla incisão em "v", sendo realizado exame macroscópica procurando identificar secreções na cavidade peritoneal e sinais de obstrução intestinal. A seguir, as possíveis aderências foram desfeitas para detectar possíveis abcessos perianastomóticos e deiscências bloqueadas. Foram considerados deiscentes todas as anastomoses que apresentaram qualquer 
vazamento do conteúdo entérico, na linha da anastomose.

Descrito os possíveis achados foi retirado um segmento contendo a anastomose com $1,5 \mathrm{~cm}$ distal e $1,5 \mathrm{~cm}$ proximal.

\section{Determinação dos níveis de hidroxiprolina}

\section{Extração}

A extração de hidroxiprolina do material coletado foi realizada segundo a técnica proposta por STEGERMANN\& STALDER, em 1967, e modificada em 1980 suprimindo a fase de secagem em estufa a vácuo. $\mathrm{O}$ tecido passara pelas seguintes etapas:

a. O tecido foi pesado e colocado em estufa a $90^{\circ} \mathrm{C}$, por 4 horas e a seguir foi pesado novamente.

b. Foi hidrolizado em ampola fechada contendo $\mathrm{HCl} 6 \mathrm{~N}$ ( $1 \mathrm{ml}$ para cada $10 \mathrm{mg}$ de tecido), em estufa a $107-110^{\circ} \mathrm{C}$, por 18 horas.

c. Foi adicionado carvão ativado puro $(100 \mathrm{mg})$ e tampão citrato/acetato (ph 6,0) $20 \mathrm{ml}$, completandose para $50 \mathrm{ml} \mathrm{com} \mathrm{H}_{2} \mathrm{O}$ tridestilada, seguindo-se agitação vigorosa em agitador excêntrico e a seguir filtragem desta suspensão.

\section{Dosagem da hidroxiprolina}

A dosagem da hidroxiprolina foi efetuada segundo a técnica de STELGEMANN\&STALDER(1967) $)^{22}$, que utiliza a cloramina $\mathrm{T}$ como agente oxidante deste aminoácido, na presença de solução de Aldeído/ $\mathrm{HCLO}_{4}$ como indutor do acoplamento do cromógeno formado.

a. Em um tubo de ensaio contendo $2 \mathrm{ml}$ do extrato obtido é adicionado, à temperatura ambiente, $1 \mathrm{ml}$ de cloramina $\mathrm{T}$, agitando-se vigorosamente em seguida em um agitador excêntrico.

b. Após 20 minutos , adiciona-se Aldeído/ $\mathrm{HCLO}_{4}$ - $1 \mathrm{ml}$, agitando-se vigorosamente em um agitado excêntrico, por 30 minutos. c. Banho-maria a $60^{\circ} \mathrm{C}$ durante 15 minutos, seguido de resfriamento em água corrente, por $10 \mathrm{mi}$ nutos.

d. Leitura espectrofotométrica, após ajuste do aparelho com o "Blanck" e teste com solução de concentração conhecida. Foram lidas a absorbância, a transmitância e a concentração para cada amostra, em comprimento de 550nm.

Para cada amostra de tecido serão realizadas duas leituras. A concentração de hidroxiprolina em ug/100 $\mathrm{mg}$ de tecido é dada pela seguinte fórmula:

$$
\mathrm{CH}=\mathrm{xC} . \mathrm{V} .100 \text {, onde }
$$$$
\text { P.S. }
$$

$\mathrm{CH}=$ concentração de hidroxiprolina em ug/100mg de tecido seco.

$\mathrm{xC}=$ média das concentrações obtidas nas duas leituras espectrofotométricas.

P.S. $=$ peso seco.

$\mathrm{V}=$ volume final da suspensão.

\section{Análise estatística}

Os dados obtidos da concentração de hidroxiprolina foram analisados estatisticamente pelo teste de Kruskal-Wallis e os escores dos indicadores histopatológicos foram comparados usando-se o teste exato da Fisher.

\section{RESULTADOS}

Foram estudados 39 animais divididos em 22 no grupo obstruído e 17 no grupo controle, lembrando que aqueles que morreram antes da realização da anastomose foram excluídos do trabalho, estes animais foram pesados antes de cada procedimento, observados possíveis complicações e colhido segmento para dosagem de hidroxiprolina (Figura 3).

Peso

Perda Ponderal

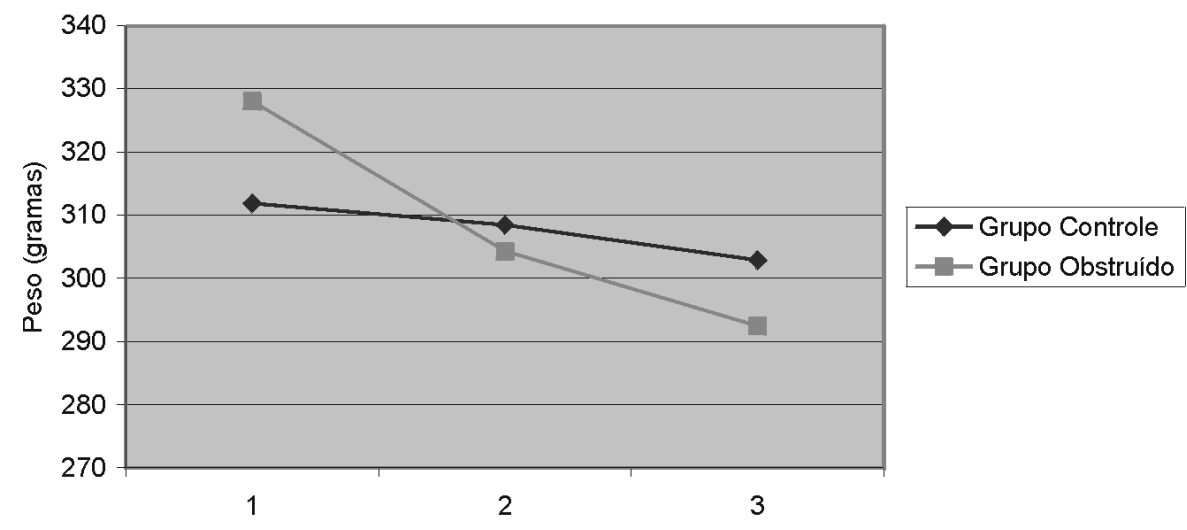

Figura 3

Procedimentos 
O grupo obstruído teve uma maior perda ponderal no período em que se realizaram os procedimentos se comparado com o grupo controle, esta mostrou diferença estatística $(p>0,05)$. Observamos que a perda é mais acentuada no grupo obstruído no período em que o cólon esta ocluído.

\section{Dosagem de Hidroxiprolina.}

A dosagem de hidroxiprolina apesar de em média ser maior no grupo obstruído (975) do que no grupo controle (872), não demonstrou diferença estatística $(\mathrm{p}<0,05)$.

\section{Complicações}

As complicações (14 ratos) foram mais freqüentes no grupo obstruído 11 ratos $(50 \%)$ do que no grupo controle, onde 3 ratos $(17,6 \%)$ tiveram complicação $(p>0,05)($ Tabela 1).

Tabela 1

\begin{tabular}{cccc}
\hline & Complicações & S/Complicações & Total \\
\hline Controle & 3 & 14 & 17 \\
Obstruído & 11 & 11 & 22 \\
\hline Total & 14 & 25 & 39 \\
\hline
\end{tabular}

As complicações observadas se dividiram em: peritonite, óbito do animal após a anastomose, íleo adi- nâmico descrito como parada do conteúdo intestinal sem uma causa mecânica identificável e fístula (Tabela 2).

Tabela 2

\begin{tabular}{cccc}
\hline Grupos & Controle & Obstruído & Total \\
Complicação & & & 3 \\
\hline Peritonite & 2 & 1 & 4 \\
Óbito & 1 & 3 & 3 \\
Íleo adinâmico & 0 & 3 & 4 \\
Fistula & 0 & 4 & 14 \\
\hline
\end{tabular}

\section{DISCUSSÃ̃O}

O método utilizado mostrou-se adequado para proposta do trabalho uma vez que as variáveis adotadas foram avaliadas de forma objetiva e os resultados obtidos comparados com a literatura.

Analisando os dados pode-se concluir que houve uma perda ponderal mais significativa no grupo obstruído provavelmente decorrente da impactação de fezes amontante que levaria a isquemia local e diminuição da absorção de substâncias contribuindo para a perda ponderal, além destas o acumula de toxinas levando a queda do estado geral e diminuição da ingesta.

A dosagem de hidroxiprolina é um método indireto de avaliar a deposição de fibras de colágeno gerado durante o processo de cicatrização da anastomose, este avalia de forma mensurável a quantidade de colágeno formado na cicatrização sendo utilizado em diversos trabalhos.

Esta técnica não demonstrou diferença estatística entre o grupo controle e obstruído, inferiu-se que uma vez ocorrendo à cicatrização da anastomose esta se desenvolve de forma semelhante nos dois grupos.

Observa-se que o número de complicações no Grupo II foi significantemente maior do que o controle. Provavelmente os mecanismos envolvidos na gênese destas estariam relacionados com a maior dificuldade técnica, desnutrição, isquemia local, translocação bacteriana e impactação de fezes.

As alterações que ocorrem durante o processo de cicatrizações na presença da obstrução intestinal ainda deve ser motivo de pesquisa futuras.

Ainda na continuidade desse trabalho serão analisados os aspectos histológicos da cicatrização. 


\section{REFERÊNCIAS}

1. Golingher JC, Graham NG, De Dombal FT. Anastomotic deiscence after anterior resection of rectum and sigmoid. Br J Surg 1970;57:109-18.

2. Irvin TT, Golingher JC. Aetiology of disruption of intestinal anastomosis. Br J Surg; 1973;60:461-4.

3. Halsted WS. Circular suture of the intestine. An experimental study. Am J Med Sci 91887;4:436-61.

4. Naresse LE. Estudo comparativo da cicatrização de anastomoses em plano único e em dói planos, no intestino delgado do cão. Avaliação anatomopatológica, estudo de força de ruptura e da hidroxiprolina tecidual. Botucatu, 1985. 104p. Dissertação mestrado. Faculdade de Medicina de Botucatu da UNESP.

5. Bailey HR, Lavoo JW, Max E, Smith KW, Hampton JM. Singlelayer continuos colorectal anastomosis. Aust N Z J Surg 1981;51:473-6.

6. Houdart R, Lavergne A, Valler P, Villet R, Rautefeuille P. Vascular evolution of single-layer end-colonic anastomosis. A micrographic study of 180 anastomoses in the rat from two to 180 days. Dis Colon Rectum 1985;28:475-80.

7. Joborn H, Ahonen J, Zederfeldt B. Healing of experimental colonic anastomoses. The effect of suture technic on collagen concentration in the colonic wal. Am J Surg 1978;135: 333-40.

8. Irvin TT, Edwards JP. Comparison of single-layer inverting, two -layer inverting, and everting anastomoses in the rabbit colon. Br J Surg 1973;69:461-4.

9. Alexander JW, Kaplan JZ, Altemeier WA. Role of suture materials in the development of wound infection. Ann.Surg 1972; 165:192-9.

10. Ehrlich HP, Tarver H, Hunt TK. Inhibitory effects of vitamin E on collagen synthesis and wound repair. Ann Surg 1972;175:235-40.

11. Hugo NE, Thompson LW, Zook EG, Bennett JE. Effect of choronic anemia on the tensile strength of healing wounds. Surgery $1969 ; 66: 741-5$.
12. Goodson WH, Hunt TK. Wound healing in experimental diabetes mellitus: importance of early insulin therapy. Surg Forum 1978;29:95-8.

13. Ferguson MK. The effect of antineoplastic agents on wound healing. Surg Gynecol Obstet 1972;154:421-9.

14. Brennan SS, Foster ME, Morgan A, Leaper DJ. Prostaglandins in colonic anastomotic healing. Dis Colon Rectum 1984;27:723-5.

15. Colin JF, Elliot P, Ellis H. Effect of uremia upon wound healing an experimental study. Br J Surg 1979;66:793-7.

16. Haan BB, Ellis H, Wilks M. The role of infection on wound healing. Surg Gynecol Obstet 1974;138:693-700.

17. Irvin TT, Hunt TK. The effect of trauma on colonic healing. Br J Surg 1974;61:430-6.

18. Buechter KJ, Boustany C, Caillouette R, Cohn I Jr. Surgical management of the cutely obstructed colon. A review of 127 cases. Am J Surg 1988;156(3Pt 1):163-8.

19. Maher M, Caldwell MP, Waldron R, Murchan P, Beesley W, Feedly TM, Tanner WA, Keane FB. Staged resection or primary anastomosis for obstructing lesions to the left colon. IrMed J 1996;89(4):138-9.

20. Thow GB. Emergency left colon resection with primary anastomosis. Dis Colon Rectum 1980;23(1):17-24

21. Deen HI, Madoff RD, Goldberg SM, Rothenberger DA. Surgical management of left colon obstruction: the University of Minnesota experience. J Am Coll Surg 1998;187(6):573-6.

22. Stegemann H, Stalder K. Determination of hidroxyproline. Clin Chim Acta 1967;18:267-73.

\section{Endereço para correspondência}

Omar Feres

Departamento de Cirurgia e Anatomia

Faculdade de Medicina de Ribeirão Preto - USP

Campus Universitário - Monte Alegre

14048-990 - Ribeirão Preto - SP 